\title{
Take us to the beach!
}

\author{
I. Diane Cooper, AHIP \\ DOI: http://dx.doi.org/10.3163/1536-5050.104.3.001
}

Or wherever you go on your summer break. Take this issue of the Journal of the Medical Library Association (JMLA), and take along a yellow highlighter, too, because you will find lots you want to mark and have available at your place of work.

\section{SOME EXAMPLES}

Do you teach or help teach evidence-based practice (EBP)? You will be interested in a systematic review of the effectiveness of teaching methods. In this review by Stephanie Swanberg, AHIP, and colleagues, over 600 studies underwent full-text review, and 49 studies underwent critical appraisal. See "Instructional Methods Used by Health Sciences Librarians to Teach Evidence-Based Practice: A Systematic Review."

Rubrics in the field of education are standardized ways to evaluate student performance. But the rubric must fit the particular student population and the rating faculty's understanding. Making a rubric fit is called norming. David Turbow and Julie Evener normed a rubric used to evaluate the quality of student work for research-based assignments. They present their results and tell us how they did it. See "Norming a VALUE Rubric to Assess Graduate Information Literacy Skills."

One day, you might find yourself searching for adverse effects, not of a medication, but of a device. Will the filters you use for retrieval of medication adverse effects work for devices? Kelly Farrah, AHIP, and colleagues checked it out. You may be surprised. See "Effectiveness of Adverse Effects Search Filters: Drugs versus Medical Devices."

For medical students and postgrads, should your library buy paper or electronic resources? What do they prefer? Does it matter at what level they are? Keith Pickett studied this at Tulane University. One size does not necessarily fit all, he found. See "Resource Format Preferences across the Medical Curriculum."

A number of articles deal with the professional roles of health sciences librarians:

- Just what do patrons think about and how do they use embedded librarians? Lindsay Blake, AHIP, and colleagues studied this at their university. Maybe we should make some changes. See "Patron Perception and Utilization of an Embedded Librarian Program."

- Trey Lemley, AHIP, describes his experience as an embedded librarian in his commentary, "Virtual Embedded Librarianship Program: A Personal View."

- Are we "off the radar?" Should we be? Sue Espe, AHIP, discusses this in her commentary, "Health Sciences Librarians off the Radar."

Who do you know who calmly guided a van full of librarians down a mountain road with no brakes? That would be our new Medical Library Association president, Teresa L. Knott, AHIP. Learn more about her life from the fascinating MLA presidential profile, "Teresa L. Knott, AHIP, Medical Library Association President, 2016-2017," by Janna C. Lawrence, AHIP, in this issue of the JMLA.

And there are more interesting articles that were in the final production stage when this editorial was written. Tell me which articles you liked and didn't like, and all your comments. 


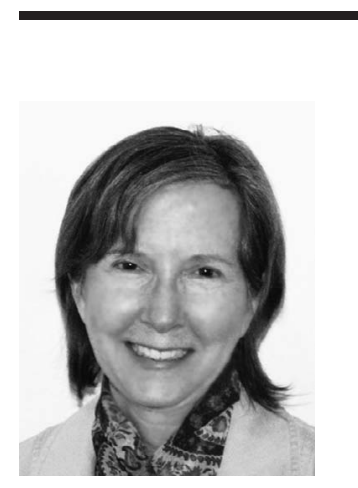

\section{AUTHOR'S AFFILIATION}

I. Diane Cooper, AHIP, jmlaeditorbox@gmail.com, Editor-in-Chief, Journal of the Medical Library Association

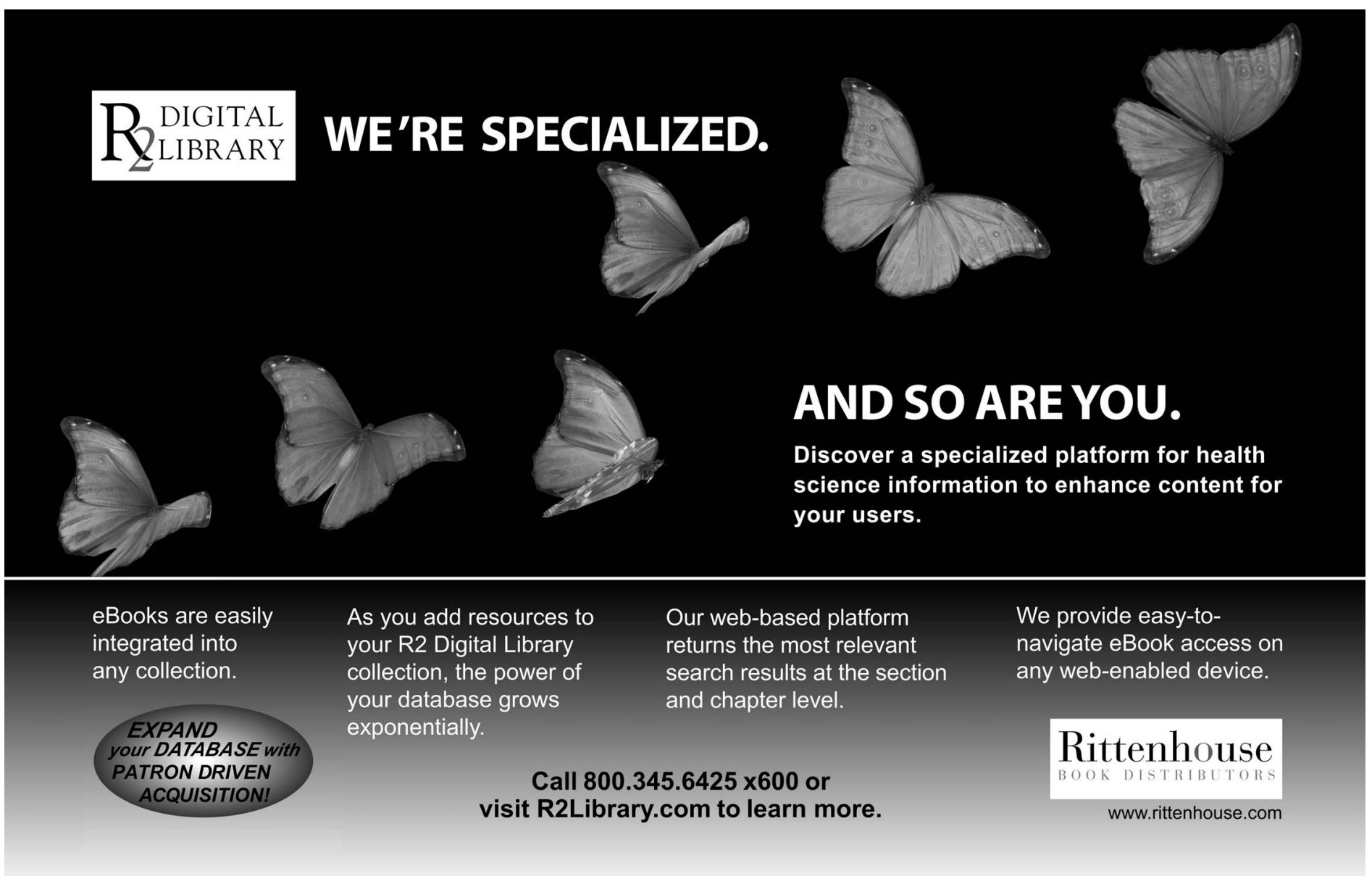

